\title{
EMPIRICAL MODEL OF DISCRETIZED COPPER ORE FLOW WITHIN THE UNDERGROUND MINE TRANSPORT SYSTEM
}

\author{
Bardzinski, P. J.\#; Krol, R. \& Jurdziak, L. \\ Faculty of Geoengineering, Mining and Geology, Wroclaw University of Science and Technology, \\ ul. Na Grobli 13/15, 50-421 Wroclaw, Poland \\ E-Mail: piotr.bardzinski@pwr.edu.pl (" Corresponding author)
}

\begin{abstract}
A model of the transport system in a copper ore mine was prepared using FlexSim software and the simulations were performed for five days. Empirical parameters were applied to each item of the transport system in order for the ore transport times to correspond to the actual conditions. Both the class- and the loading point-specific haul truck courses were based on the five-day schedule. Mean inter-arrival times were modelled for haul trucks according to empirical histograms. The ore portions were discretized and their masses were based on haul truck load capacities. The simulations were performed for twelve variants covering the unavailability of different ore sources. The recorded statistics include ore provenience, lithology, $\mathrm{Cu}$ content and tag survival rate for RFID-tagged ore variants. The model represents the new way of solving the problem of ore mixing in a conveyor beltbased transport system. Adoption of the proposed scheme, will allow the enrichment plant managers to adjust the milling and crushing parameters to the lithology of the ore before it will leave the mine. The model allows to pinpoint the areas in the mine that produce certain demanded lithological factions and helps the managers to choose the most desirable pattern of the mining schedule and forecast the economical outcome.
\end{abstract}

(Received in December 2018, accepted in May 2019. This paper was with the authors 1 month for 2 revisions.)

Key Words: $\quad$ Ore Flow, Transport System, Quality Management, Ore Lithology, Metal Yield, Empirical Model

\section{INTRODUCTION}

Production and transport modelling is aimed at process costs optimization and energy saving with least resources engaged. One of such tools, the FlexSim package [1-3], was recently applied in various branches of industry. These include simulating the process of mass customization of products [4], performance improvement of airport security control system [5, 6], fully-automatic sorting system design [7], dynamic redesign of the production system [8], lot sizing optimization [9], order batching algorithm for pick-and-pass system [10], production logistics optimization [11], production of tapered roller bearings [12], supply chain management [13-15], mixed line production in automotive sector [16] or implementation of lean manufacturing system in printing facility [17].

Among many industrial applications, the popularity of FlexSim is raising in the area of mining. The program was recently used for the simulation of surface mining production processes [18]. As reported by Libing et al. [19] as well as by Chen and Shi [20], the software was also utilized to study aluminium ore transport in a Chinese bauxite strip mine. The authors of the latter work [21] focused their model on microscopic dynamic dispatching scheme and on probability distribution fitting of $\mathrm{Al}$ ore grade per truck. In the current study, a different approach was adopted, based on the exact lithology and $\mathrm{Cu}$ content of the sources and on empirical histograms of haul truck inter-arrival times, together with the empirical data concerning schedules for different parts of the mining transport system. The aim was to reliably represent real conditions occurring in the mine over a chosen period and equip the Ore Enrichment Plant (OEP) operators with a new useful tool to adjust the ore processing parameters, as discussed by Jurdziak et al. [22]. 


\section{COMPUTATIONAL METHODS}

An item, which flows through the transport system, here, referred to as a pellet, is a discrete portion of mined ore. The term was introduced to represent either an ore portion itself or an RFID tag ascribed to such an ore portion, as in an experiment performed on location in a mine [22] and described elsewhere [23]. It carries information about the loading point number, haul truck class, lithology, copper content in the transported lithologic fractions and mass. It is worth noting that in the actual mine, the block-crushing devices are placed above each loading point and their operators are reporting the number and class of the arriving haul trucks that transport the ore from the mining front to the nearest loading point. Division by classes is based on haul truckload capacity in tons: A (15 t), B (12 t) and C (8t). A comparison between the aggregated ore mass measured on the belt with scales located on the P6 belt conveyor and the reports filed by the block-crushing device operator revealed only minor differences of about $7 \%$. Thus, the haul truckload capacity poses a good approximation of the discretized ore portion's mass and was ascribed to each pellet.

Note that supplementary material (including tables and figures) is available online on http://www.zsm.pwr.wroc.pl/Supplementary_material.pdf. The data about the ore lithology, presented in supplementary Table S1, were taken from the MOPRONA ore production monitoring system [24], which contains the analyses of face samples acquired from the mining fronts at KGHM's worldwide enterprise mines.

Class- and loading point-specific haul truck courses were based on a five-day schedule. Mean inter-arrival time given in seconds, was modelled according to haul truck class-specific discrete empirical distributions. The latter were based on the empirical histograms of haul truck inter-arrival times. Both the transport system and the skips were scheduled on a 24-hour basis. All belt conveyors were scheduled to be offline from 5 to $7 \mathrm{AM}$ and at $6 \mathrm{PM}$ due to rock blasting, shift change and maintenance works [25-27]. Consequently, down time of the skips was scheduled from 6 to 11 PM.

Empirical parameters were applied to each item of the transport system, according to supplementary Tables S2 and S3. For belt conveyors, the conveyor length, belt speed and distance from the loading point to the head pulley were set. Note that the real proportions and lengths are taken into account in the simulations, while they are not necessarily represented in the 3D visualization of the model. Separator S214 sends the pellet to its two output ports, using the round-robin algorithm. The durations of the loading and unloading cycles of the skips were set to $88 \mathrm{~s}$ each, with allowance for the time needed for the upward and downward movement of the skip in a real mine. Maximum skip speed was set to $16 \mathrm{~m} / \mathrm{s}$.

The Pellet Queue, placed after the OEP in the 3D mine model, sends the pellets either to the Pellet Counter processor or to the Destroyed Pellet sink, based on a given percentage. The pellets to be lost along their way to the OEP are randomly selected. For each simulation variant, several statistics at the OEP were recorded, as shown in Fig. 1. First are the statistics of the ore provenience. These include the number of pellets delivered from each source, source name and haul truck class, total mass of rocks transported, lithology and $\mathrm{Cu}$ content. Second statistics contain information about the total mass of aggregated ore reaching the OEP every hour, together with its lithology and $\mathrm{Cu}$ content. Finally, the number of the recorded and destroyed pellets, which passed the whole transport system, i.e. between the source and the OEP, was provided for each hour.

The actual FlexSim model of the ZG Lubin mine was presented in Fig. 2 and supplementary Figs. S1 - S2. It shows that the mine transport system was divided into node or ore reloading points, in similar manner as described by Straka et al. [28]. Every experimental run was set to five working days, from Monday to Friday, which is equal to $432000 \mathrm{~s}$. During the five-day working period of ZG Lubin mine, as described in D5.2 Report, the following 
mining departments were active: G-1, G-4 and G-9. Within the G-1 department, the run-ofmine ore was transported by belt conveyors A183 and M41a from loading points L71 and LP22, respectively. Within the G-4 department, belt conveyor M41a was transporting the ore from loading points LP18, LP13 and LP8. Belt conveyor L52 was transporting the ore from loading points LP10 and LP24. Within the G-9 department, two belt conveyors were used: L142 (loading points LP11 and LP6) and L910b (loading points LP14 and LP7).

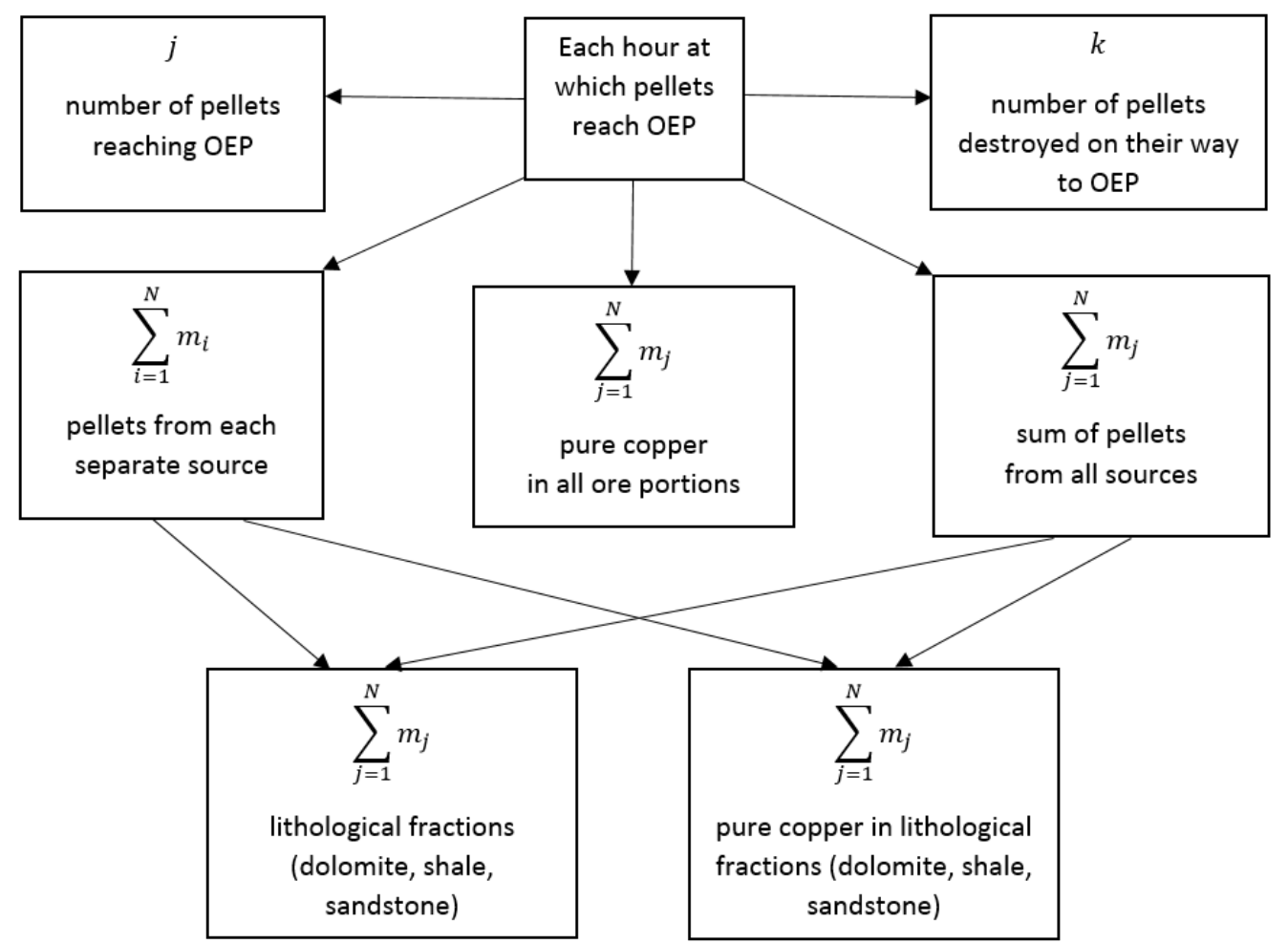

Figure 1: Statistics collection scheme in the Flexsim model of the ZG Lubin mine.

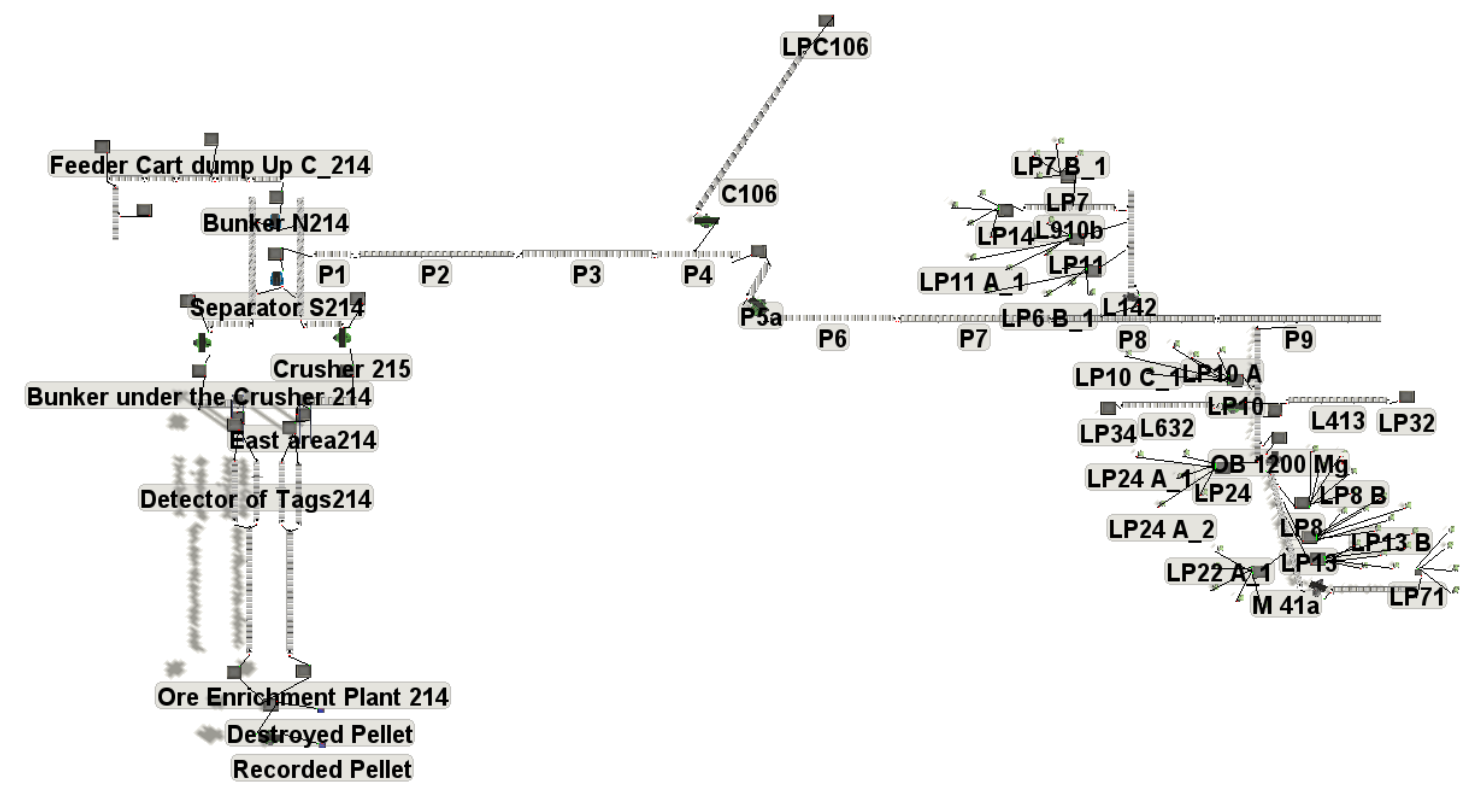

Figure 2: FlexSim model of the ZG Lubin mine.

Table I lists the selected simulation variants. Note that the table includes only belt conveyors fed with the ore hauled directly from the loading points. Other belt conveyors were also involved in each simulation, according to the scheme presented in Fig. 2. 
Table I: Simulation variants selected in the calculations.

\begin{tabular}{|c|c|c|c|}
\hline $\begin{array}{c}\text { Simulation } \\
\text { variant } \\
\text { number }\end{array}$ & $\begin{array}{l}\text { Ore yielding mining department (loading points) } \\
\text { considered }\end{array}$ & $\begin{array}{l}\text { Belt conveyors } \\
\text { involved }\end{array}$ & $\begin{array}{l}\text { Pellet survival } \\
\text { rate }(\%)\end{array}$ \\
\hline V1 & \multirow{4}{*}{$\begin{array}{l}\text { G-1 (L71, P22), G-4 (LP18, LP13, LP8, LP10, } \\
\text { LP24), G-9 (LP11, LP6, LP14, LP7) }\end{array}$} & \multirow{4}{*}{$\begin{array}{l}\text { A183, M41a, L52, } \\
\text { L142, L910b }\end{array}$} & 100 \\
\hline $\mathrm{V} 2$ & & & 90 \\
\hline V3 & & & 80 \\
\hline V4 & & & 70 \\
\hline V5 & $\begin{array}{l}\text { G-1 (L71, P22), G-4 (LP18, LP13, LP8, LP10, } \\
\text { LP24) }\end{array}$ & A183, M41a, L52 & \multirow{6}{*}{100} \\
\hline V6 & $\begin{array}{l}\text { G-4 (LP18, LP13, LP8, LP10, LP24), G-9 (LP11, } \\
\text { LP6, LP14, LP7) }\end{array}$ & $\begin{array}{l}\text { M41a, L52, L142, } \\
\text { L910b }\end{array}$ & \\
\hline V7 & G-1 (L71, P22), G-9 (LP11, LP6, LP14, LP7) & $\begin{array}{l}\text { A183, M41a, L52, } \\
\text { L142, L910b }\end{array}$ & \\
\hline V8 & G-9 (LP11, LP6, LP14, LP7) & L142, L910b & \\
\hline V9 & $\begin{array}{l}\text { G-1 (L71, P22), G-4 (LP18, LP13, LP8, LP10, } \\
\text { LP24), G-9 (LP11, LP6) }\end{array}$ & $\begin{array}{l}\text { A183, M41a, L52, } \\
\text { L142 }\end{array}$ & \\
\hline V10 & $\begin{array}{l}\text { G-1 (P22), G-4 (LP18, LP13, LP8, LP10, LP24), } \\
\text { G-9 (LP11, LP6, LP14, LP7) }\end{array}$ & $\begin{array}{l}\text { M41a, L52, L142, } \\
\text { L910b }\end{array}$ & \\
\hline
\end{tabular}

The variants are as follows:

V1. A model including the loading points within all mining departments and covering the 5day period, in accordance with the data acquired from the mine and collected in D5.2 Report. $100 \%$ pellet survival rate was assumed;

V1a. Identical to V1, but skips were scheduled to 24-hour operational time, without down time between $6 \mathrm{PM}-11 \mathrm{PM}$;

V1b. Identical to V1, but all belt conveyors were scheduled to 24-hour operational time, without the 4-hour down time (5 - 7 AM and $6 \mathrm{PM}$ );

V2. Mining departments considered as in V1, but $90 \%$ pellet survival rate was assumed;

V3. Mining departments considered as in V1, but $80 \%$ pellet survival rate was assumed;

V4. Mining departments considered as in V1, but $70 \%$ pellet survival rate was assumed.

For the following variants, the pellet survival rate was set to $100 \%$, while several loading points were stopped for the five-day (or 120 hour) period:

V5. Mining at the G-9 department stopped (belt conveyors L-910b and L-142);

V6. Mining at the G-1 department stopped (loading points L71 and LP-22);

V7. Mining at the G-4 department stopped (loading points LP8, LP13, LP10, LP24 and LP18);

V8. Departments G-1 and G-4 were inactive (belt conveyors L52, M41a and A183);

V9. Only belt conveyor L910b stopped;

V10. Only belt conveyor A183 stopped.

\section{RESULTS AND DISCUSSION}

The V1 variant stands for a model representation of the actual conditions observed in the ZG Lubin mine within a five-day working period. This variant was used for reference purposes. The first pellet, hauled from loading point number 6 (LP6) appeared at the OEP in the $17^{\text {th }}$ hour of the experiment. Within the $18^{\text {th }}$ hour, the recorded pellets came from G-9 department (LP6, LP11, LP7, LP14) and G-4 department (LP10, LP24, LP8, LP13 and LP18). The first pellet from G-1 department (LP22 and LP71) arrived at the OEP in the $19^{\text {th }}$ hour of the experiment. According to supplementary Fig. S3, primary lithological fractions were sandstone and shale, with only minor, and thus negligible, contribution of dolomite. The 
contribution of sandstone was dominant, while shale mass was about one third of sandstone mass. supplementary Fig. S4 shows that pure copper yield from shale fraction was $70-90 \%$ that from sandstone.

Variants V1a and V1b were considered in order to identify the possible influence of the schedule of skips and transport system on the total copper yield, computed on an hourly basis. Total ore mass may serve as an adequate measure for comparison. A periodicity of interruptions followed by surges in ore production was observed. They correspond to the rock blasting at the mining fronts and to the scheduled maintenance works in the actual mine. As can be seen from Fig. 3, the down time of the belt conveyor system in the mine is responsible for the accumulation and sudden release of ore. Comparison of variants V1 and V1a leads to a conclusion that the operational time of the skips contributes less to the observed changes in the transported ore.

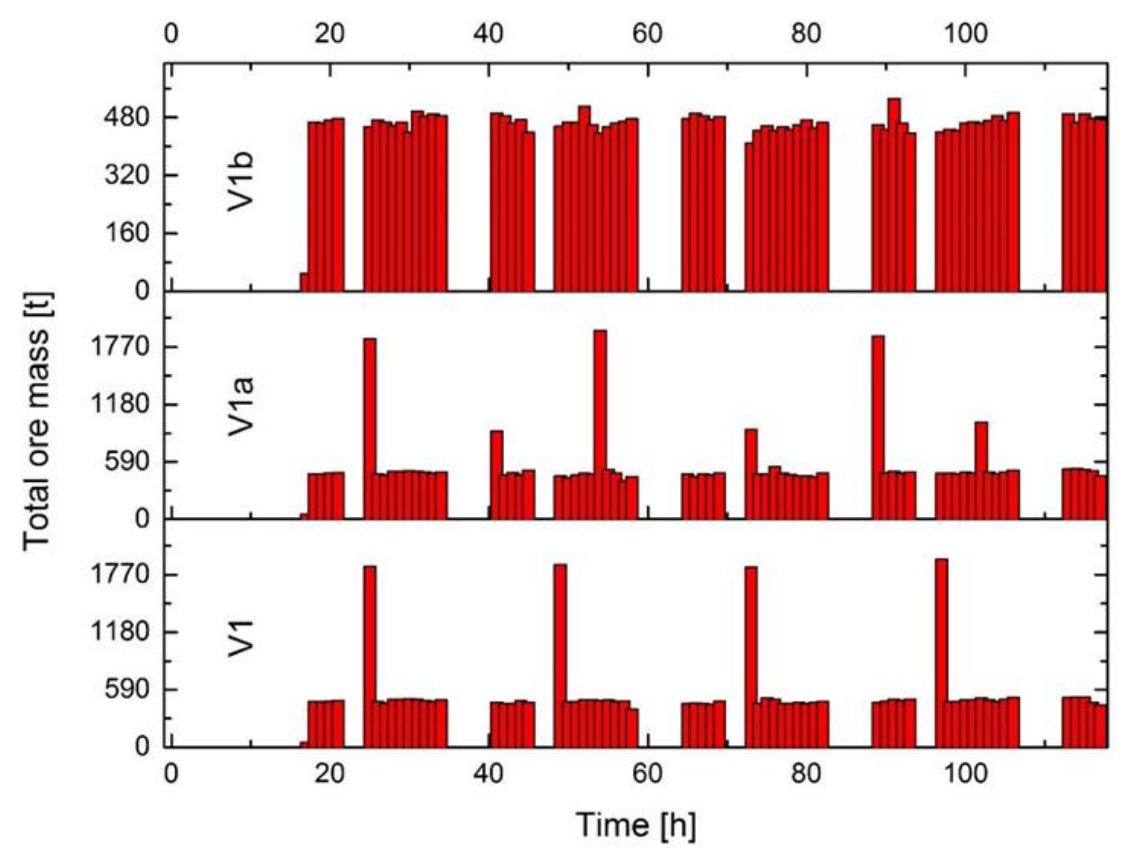

Figure 3: Total ore mass in V1, V1a and V1b variants of FlexSim simulation.

Variants 2 to 4, can give insight into the experiments, in which ore portions were marked with the RFID tags (i.e. pellets) and some part of them were destroyed along their way to the OEP. Note that in the above variants, the quantitative information about the transported mass was lost, because the pellet in the model acts as a discrete mass-bearing object. The data presented in Fig. 4 show how the number of the recorded pellets will be affected by a particular pellet survival rate. In real conditions, the RFID tags can be trapped in mud, or crushed by the larger rock pieces or block-crushing devices at the loading points as well as in the crushers before the skips. Such potentiality should also be allowed for in the model.

Variants 5-10 stand for the conditions in which one or more loading points are temporarily inactive due to typical mine-related circumstances. These include a seismic event, an outburst or rock burst, mining front depletion or a managerial decision. When compared, the variants could provide some information about the contribution of each mining department to the total ore yield and could show how the lithology and ore composition at the OEP change when such conditions occur. This additional information could allow the OEP operators to adjust the crusher working parameters to the dominant lithologic fractions, and thus translate into substantial energy savings.

Total ore mass and the corresponding $\mathrm{Cu}$ yield collected at the OEP after 5 days of simulation were presented in supplementary Fig. S5. Dashed line is a guide to the eye for 
subtle deviations from the V1 variant. A comparison of variants V7 and V8 with variant V1 shows the dominant contribution of the G-4 mining department to the total ore and $\mathrm{Cu}$ yield.

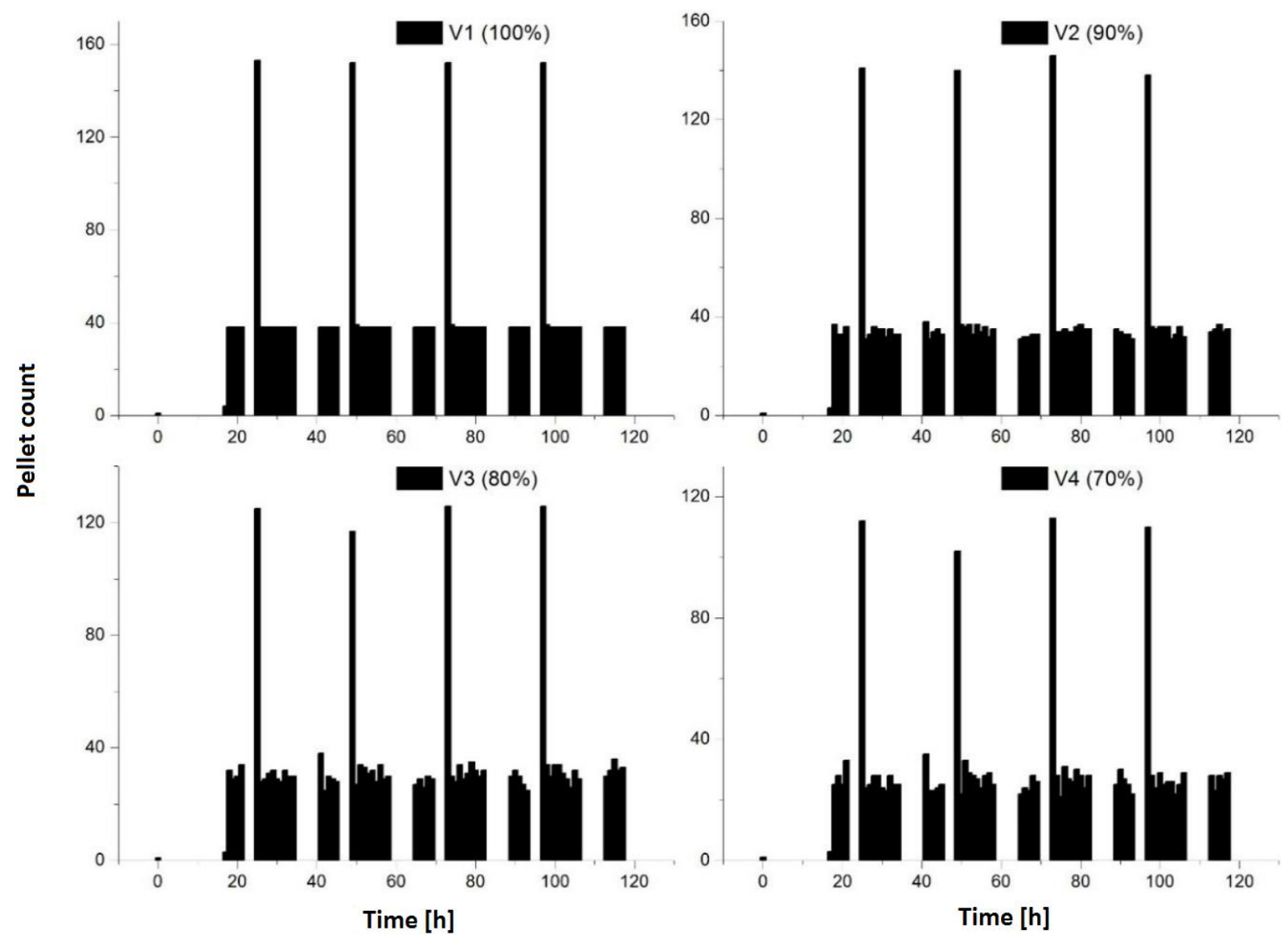

Figure 4: Number of recorded and destroyed pellets in V1 - V4 variants of FlexSim simulation.

Interestingly, while belt conveyors L52, M41a and A183 were inactive (V8), the total ore and $\mathrm{Cu}$ yield was the lowest among the selected variants, while in variant $\mathrm{V} 10$, in which only belt conveyor A183 was offline, additional $415 \mathrm{t}$ of ore and $4.1 \mathrm{t}$ of $\mathrm{Cu}$ reached the OEP. When both loading points of the mining department G-1 were inactive (V6), additional $297 \mathrm{t}$ of ore, but also $4.6 \mathrm{t}$ less $\mathrm{Cu}$ were produced. Importantly, in every variant, the quantity of ore delivered by currently working haul trucks was the same. According to supplementary Table $\mathrm{S} 1$, the ore produced by the G-4 department is richer in shale fraction than the ore mined in the G-1 department, with comparable $\mathrm{Cu}$ content in the shale. The data presented in Table II demonstrate that in variants V6, V9 and V10, more pellets from the G-4 department, especially from loading points LP8, LP10 and LP13, reached the OEP. Apparently, when the shale-depleted sources are rendered inactive, the ore from other departments, in this case from G-4, reaches the OEP in a shorter time. The same observation was made for variant V9, in which only belt conveyor L910b was offline. In the case of variant V9, more pellets from departments G-1 and G-4 reached the OEP. Although loading points LP7 and LP14 were offline and $21 \mathrm{t}$ less ore were processed, $0.3 \mathrm{t}$ of extra $\mathrm{Cu}$ was obtained at the OEP.

The masses of lithological fractions produced in each of the abovementioned variants are presented in Fig. 5. The data show that the surges of the ore mass transported to the OEP were caused by the scheduling of haul trucks at G-4 mining department, but its influence is less significant than of the down times of belt conveyors in the mine (see Fig. 3). The G-4 mining department is the primary source of shale fraction, while department G-9 delivers more sandstone. Loading points numbers 14, 7 and L71 have no significant influence on the 
lithology of the ore transported to the OEP. A comparison of the corresponding changes in $\mathrm{Cu}$ content may be interesting, as it could allow the OEP operators to adjust the parameters of chemical after treatment of the processed ore. As shown in Fig. 6, stopping the L142 belt conveyor located at mining department G-9 results in the dominant contribution of $\mathrm{Cu}$ bearing minerals in the shale fraction. When department $\mathrm{G}-4$ was closed, the amount of $\mathrm{Cu}$ in shale and sandstone was approximately equal. Stopping belt conveyor L910b has a negligible impact on $\mathrm{Cu}$ content in the transported ore. Closing of loading point L71 leads to substantial increase in shale-to-sandstone $\mathrm{Cu}$ content ratio on the last day of the experiment possibly due to the scheduling of haul trucks among the loading points.

Table II: Pellet count for selected variants after 5-day simulation run.

\begin{tabular}{|c|c|c|c|c|c|}
\hline Mining & Loading & \multicolumn{4}{|c|}{ Simulation variant } \\
\cline { 2 - 6 } department & point & V1 & V6 & V9 & V10 \\
\hline \multirow{4}{*}{ G-1 } & L71 & 212 & 0 & 270 & 0 \\
\cline { 2 - 6 } & LP22 & 224 & 0 & 280 & 245 \\
\hline \multirow{4}{*}{ G-4 } & LP18 & 149 & 144 & 144 & 151 \\
\cline { 2 - 6 } & LP13 & 217 & 323 & 328 & 271 \\
\cline { 2 - 6 } & LP8 & 481 & 571 & 579 & 516 \\
\cline { 2 - 6 } & LP10 & 368 & 458 & 461 & 382 \\
\cline { 2 - 6 } & LP24 & 33 & 31 & 29 & 35 \\
\hline \multirow{4}{*}{ G-9 } & LP11 & 241 & 254 & 260 & 248 \\
\cline { 2 - 6 } & LP6 & 444 & 507 & 532 & 458 \\
\cline { 2 - 6 } & LP14 & 106 & 138 & 0 & 144 \\
\cline { 2 - 6 } & LP7 & 422 & 459 & 0 & 445 \\
\hline
\end{tabular}

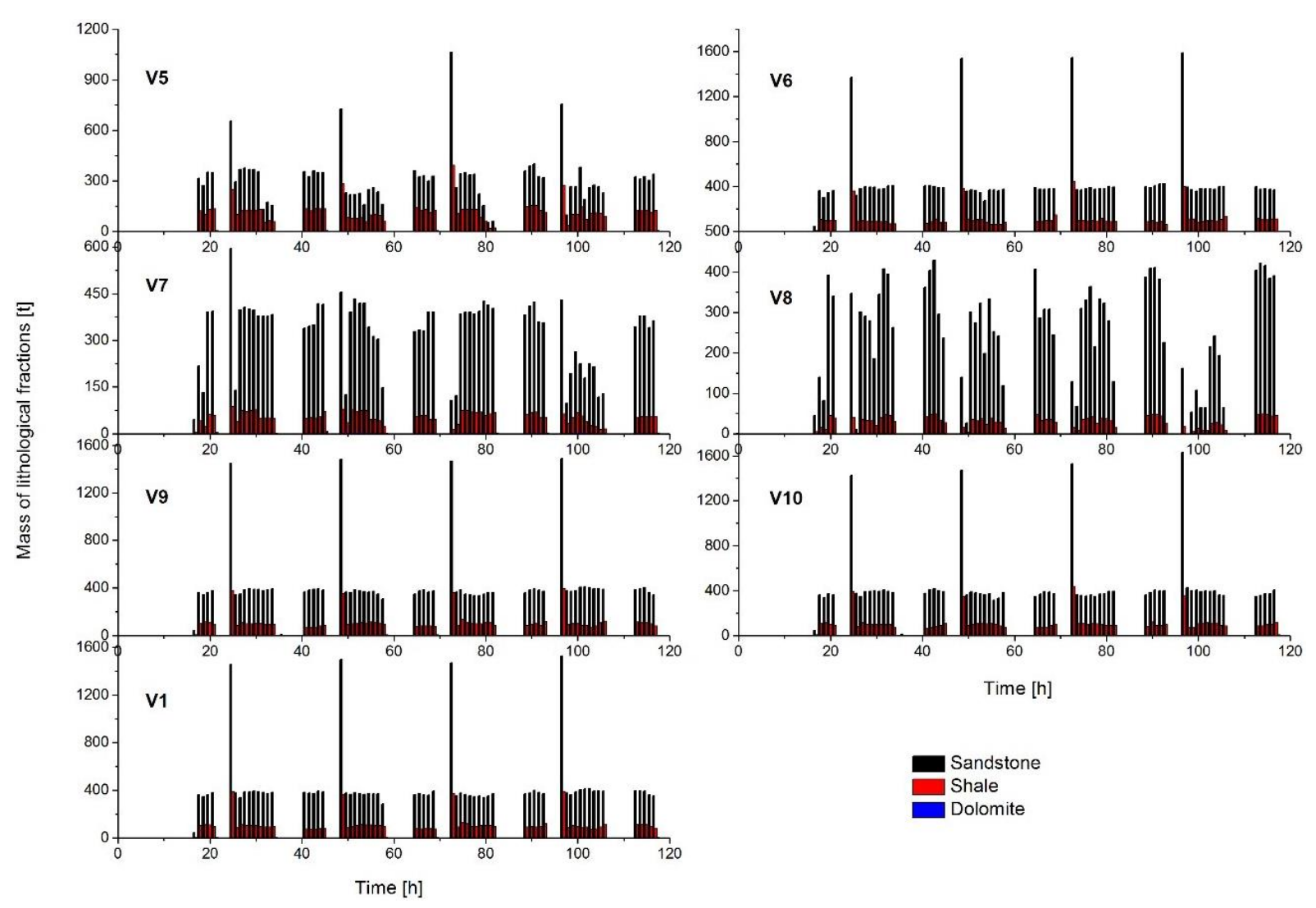

Figure 5: Mass of lithological fractions in the V1, V5 to V10 variants of FlexSim simulation. 


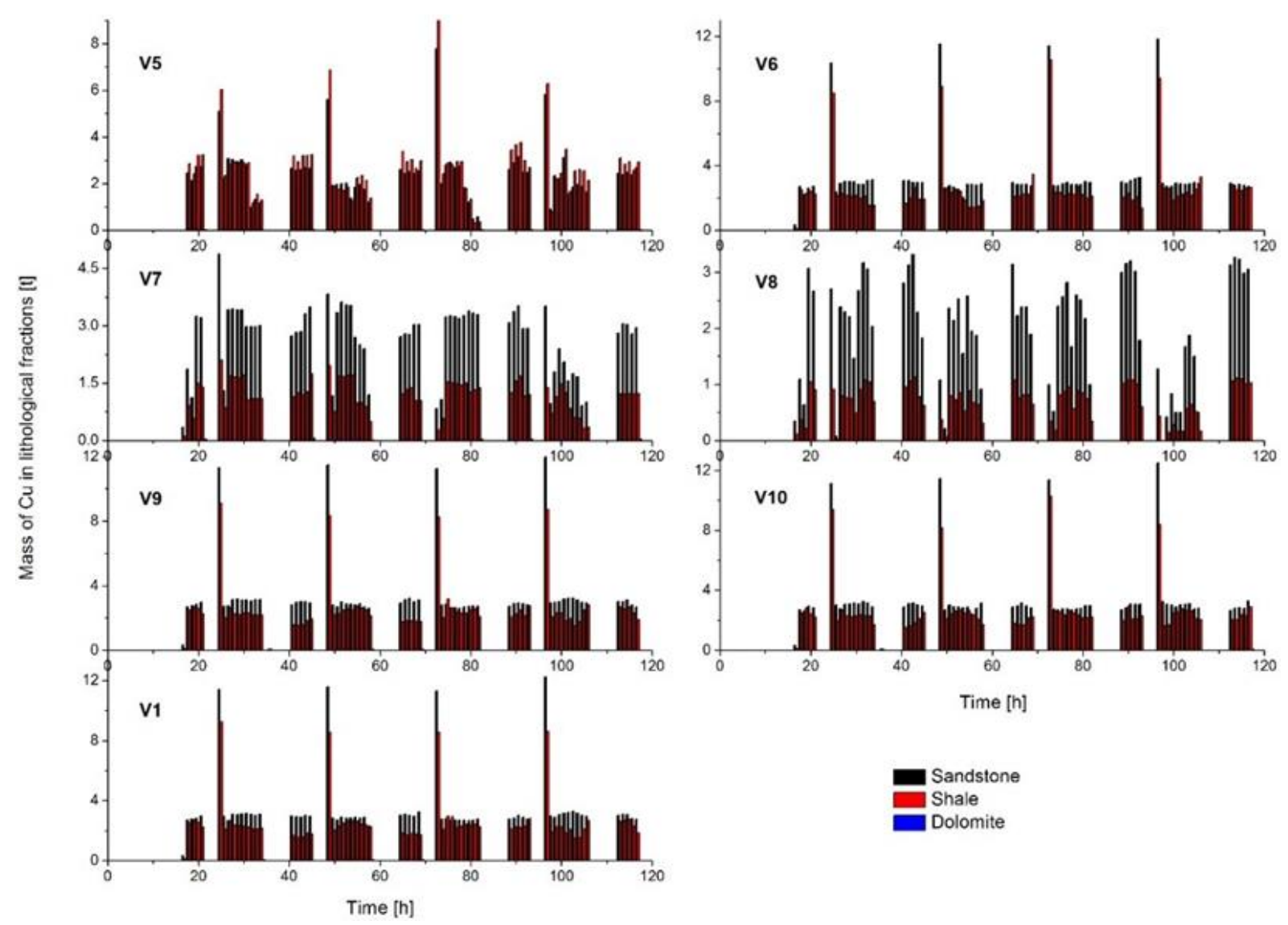

Figure 6: Mass of $\mathrm{Cu}$ in lithological fractions in the V1, V5 to V10 variants of FlexSim simulation.

\section{CONCLUSIONS}

The study was conducted in order to adjust the flotation process parameters to the composition and lithology of the run-of-mine ore fed to the Ore Enrichment Plant.

The total ore mass after 5 days in the V1 simulation variant was $35,835 \mathrm{t}$, compared to $62,060 \mathrm{t}$, as read from the belt scale located in conveyor P6 (see Fig. 2) in the actual mine. It was approximately $42 \%$ smaller than the mass from the data acquired by the personnel of the mine. Some limitation of the model consists in the fact that it cannot allow for the ore portions transported from sources not recorded in shift reports, e.g. from development works. In order to estimate the ore lithology and its copper content, appropriate data must be associated with each ore source, together with ore mass and the frequency of haul truck courses.

The study revealed that the down time of the belt conveyor system in the mine was responsible for the accumulation and sudden release of the ore. The interruptions were due to rock blasting at the mining fronts as well as to the scheduled maintenance works. The second reason for the surge of the ore mass transported to the OEP was the schedule of haul trucks at the G-4 mining department.

The study also demonstrated how the number of the recorded pellets was affected by a particular pellet survival rate, when ore portions were marked with the RFID tags and part of them were destroyed along their way to the OEP. As the model is capable of simulating such situations, it could be used in the experimental ore marking in the actual mine, thus aiding the simulation of actual conditions in the experiment.

Comparison of the different variants showed that when some division haulage conveyors were out of use, the ore from other, active departments reached the OEP in a shorter time. This phenomenon is due to the position of the ore portions in the queue on the main haulage 
conveyors. When shale-depleted sources are rendered inactive, higher $\mathrm{Cu}$ yields are possible. The simulations showed the dominant contribution of the G-4 mining department to the total ore and $\mathrm{Cu}$ yield.

Primary lithological fractions were sandstone and shale, with only minor and thus negligible contribution of dolomite. The G-4 mining department is a primary source of shale fraction while the G-9 department delivers more sandstone. Loading points number L910b at department G-9 and L71 at department G-1 have no significant influence on the lithology of the ore transported to the OEP. However, closing the L142 belt conveyor located at department G-9 results in the dominant contribution of Cu-bearing minerals in the shale fraction. When department G-4 was closed, the amount of $\mathrm{Cu}$ in shale and sandstone was approximately equal.

The study shows novel solution investigated with respect to the case study, contributing to the areas of operations management and quality control. First and foremost, we shown the new way of solving the problem of ore mixing in the conveyor belt-based transport system. It was driven by its economic impact on both crushing machines lifetime and the metal yield after the flotation process. Adoption of the proposed scheme, will allow the OEP operators to adjust the milling and crushing parameters to the lithology of the ore before it will arrive at the OEP. The model allows to pinpoint the areas in the mine that produce certain demanded lithological factions and helps the managers to choose the most desirable pattern of the mining schedule. This includes the decisions about economic viability of certain mining fronts exploitation and throughput capacity optimization.

The proposed model was the first milestone towards creating the complex mine transport monitoring system. As it was shown, the current model is prone to underestimation of the total ore yield due to insufficient data input. Thus, the next step in its application should be the addition of customized scripts that allow its connection with a remote server, delivering the lithology data from the MOPRONA system, updated on a daily basis. Employment of location sensors in each of the transporting vehicles could improve the inter-arrival time statistics. Setting up the RFID tags in each of the lithological layer at the mining face before rock blasting could help to model the order in which they fall and are subsequently picked up by the haul trucks. This could further improve the description of the lithology reaching the OEP. The RFID experiment could be repeated using one of visual recognition methods that allow the online distinction between the lithological factions while transporting the rock mass on the conveyor belt.

\section{ACKNOWLEDGEMENTS}

This work was partly supported by the Framework Programme for the Research and Innovation Horizon 2020 under the grant agreement No. 636834 (DISIRE) and by the Polish Ministry of Science and Higher Education as scientific project No. 0401/0048/18.

\section{REFERENCES}

[1] Gelenbe, E.; Guennouni, H. (1991). FLEXSIM: a flexible manufacturing system simulator, European Journal of Operational Research, Vol. 53, No. 2, 149-165, doi:10.1016/03772217(91)90131-E

[2] Lavery, E.; Nordgren, B.; King, C.; Hullinger, R. (2005). Flexsim modeling environment, Proceedings of Asian Simulation Conference $/ 6^{\text {th }}$ International Conference on System Simulation and Scientific Computing, 1667-1670

[3] Nordgren, W. B. (2003). FlexSim simulation environment, Proceedings of the 2003 Winter Simulation Conference, Vol. 1, 197-200, doi:10.1109/WSC.2003.1261424 
[4] Chen, S.-Y.; Fan, S.-H.; Xiong, J.-W.; Zhang, W.-Q. (2017). The design and development of Flexsim/JMP based quality simulation system for mass customization, Proceedings of the 2016 International Forum on Mechanical, Control and Automation, Advances in Engineering Research, Vol. 113, 567-573, doi:10.2991/ifmca-16.2017.87

[5] Kierzkowski, A.; Kisiel, T. (2017). A model of check-in system management to reduce the security checkpoint variability, Simulation Modelling Practice and Theory, Vol. 74, 80-98, doi:10.1016/j.simpat.2017.03.002

[6] Kierzkowski, A.; Kisiel, T. (2017). Simulation model of security control system functioning: A case study of the Wroclaw Airport terminal, Journal of Air Transport Management, Vol. 64, Part B, 173-185, doi:10.1016/j.jairtraman.2016.09.008

[7] Pan, F.; Yu, D.; Wang, M. (2016). Simulation design of express sorting system - example of SF's sorting center, Chemical Engineering Transactions, Vol. 51, 457-462, doi:10.3303/CET1651077

[8] Bendato, I.; Cassettari, L.; Mosca, M.; Mosca, R.; Rolando, F. (2015). New markets forecast and dynamic production redesign through stochastic simulation, International Journal of Simulation Modelling, Vol. 14, No. 3, 485-498, doi:10.2507/IJSIMM14(3)10.307

[9] Zhou, F. L.; Wang, X.; He, Y. D.; Goh, M. (2017). Production lot-sizing decision making considering bottle-neck drift in multi-stage manufacturing system, Advances in Production Engineering \& Management, Vol. 12, No. 3, 213-220, doi:10.14743/apem2017.3.252

[10] Pan, J. C.-H.; Shih, P.-H.; Wu, M.-H. (2015). Order batching in a pick-and-pass warehousing system with group genetic algorithm, Omega, Vol. 57, Part B, 238-248, doi:10.1016/j.omega.2015.05.004

[11] Wang, Y. R.; Chen, A. N. (2016). Production logistics simulation and optimization of industrial enterprise based on Flexsim, International Journal of Simulation Modelling, Vol. 15, No. 4, 732 741, doi:10.2507/IJSIMM15(4)CO18

[12] Malega, P.; Kadarova, J.; Kobulnicky, J. (2017). Improvement of production efficiency of tapered roller bearing by using Plant Simulation, International Journal of Simulation Modelling, Vol. 16, No. 4, 682-693, doi:10.2507/IJSIMM16(4)10.405

[13] Grzybowska, K.; Kovacs, G. (2017). The modelling and design process of coordination mechanisms in the supply chain, Journal of Applied Logic, Vol. 24, Part A, 25-38, doi:10.1016/j.jal.2016.11.011

[14] Hoffa, P.; Pawlewski, P. (2015). Simulation of supply chain with disturbances using Flexsim Case study, International Conference on Practical Applications of Agents and Multi-Agent Systems (PAAMS 2015), Communications in Computer and Information Science, Vol. 524, 90101, doi:10.1007/978-3-319-19033-4_8

[15] Szczepanski, E.; Zak, J.; Jacyna-Golda, I.; Murawski, J. (2017). Simulation support of freight delivery schedule in urban areas, Procedia Engineering, Vol. 187, 520-525, doi:10.1016/j.proeng.2017.04.409

[16] Cao, S.; Chen, Y.; Chen, C. (2016). Work hours and sorting balancing study of one auto mixed line, 2016 International Conference on Mechanical, Manufacturing, Modeling and Mechatronics (IC4M 2016), MATEC Web of Conferences, Vol. 51, Paper 01009, 6 pages, doi:10.1051/matecconf/20165101009

[17] Tang, S.; Ng, T.; Chong, W.; Chen, K. (2016). Case study on lean manufacturing system implementation in batch printing industry Malaysia, $3^{\text {rd }}$ International Conference on Manufacturing and Industrial Technologies, MATEC Web of Conferences, Vol. 70, Paper 05002, 4 pages, doi:10.1051/matecconf/20167005002

[18] Checinski, S.; Witt, A. (2015). Modelling and simulation analysis of mine production in 3D environment, Mining Science, Vol. 22, 183-191, doi:10.5277/msc152215

[19] Libing, Y.; Hanhong, C.; Yuncai, C.; Haiyang, Y. (2008). Simulating and optimizing of logistics system in strip mines, $3^{\text {rd }}$ International Symposium on Modern Mining \& Safety Technology Proceedings, 138-143

[20] Chen, C.; Shi, L. (2017). Simulating and optimizing of tramcar transportation attempter in open pit mine, Proceedings of the $20172^{\text {nd }}$ International Conference on Modelling, Simulation and Applied Mathematics (MSAM 2017), Advances in Intelligent Systems Research, Vol. 132, 29-33, doi: $\underline{10.2991 / \mathrm{msam}-17.2017 .8}$ 
[21] Jurdziak, L.; Kawalec, W.; Król, R. (2017). Application of FlexSim in the DISIRE project, Studies \& Proceedings of the Polish Association for Knowledge Management, Vol. 84, 87-96

[22] Jurdziak, L., Kawalec, W., Król, R. (2018). Study on tracking the mined ore compound with the use of process analytic technology tags, Burduk, A.; Mazurkiewicz, D. (Eds.), Intelligent Systems in Production Engineering and Maintenance - ISPEM 2017, Springer, Cham, 418-427, doi:10.1007/978-3-319-64465-3_40

[23] Bardzinski, P. J.; Walker, P.; Krol, R.; Kawalec, W. (2018). Simulation of random tagged ore flow through the bunker in a belt conveying system, International Journal of Simulation Modelling, Vol. 17, No. 4, 597-608, doi:10.2507/IJSIMM17(4)445

[24] Jurdziak, L.; Krol, R.; Kawalec, W. (2017). Variation of ore grade transported by belt conveyors to processing plants, Physicochemical Problems of Mineral Processing, Vol. 53, No. 1, 656-669, doi:10.5277/ppmp170151

[25] Bajda, M. (2017). Laboratory tests of conveyor belt parameters affecting its lifetime, Science and Technologies in Geology, Exploration and Mining, $17^{\text {th }}$ International Multidisciplinary Scientific GeoConference SGEM 2017, 495-502, doi:10.5593/sgem2017/13/S03.063

[26] Stefaniak, P.; Wodecki, J.; Zimroz, R. (2018). Maintenance management of mining belt conveyor system based on data fusion and advanced analytics, Timofiejczuk, A.; Lazarz, B. E.; Chaari, F.; Burdzik, R. (Eds.), Advances in Technical Diagnostics, Springer, Cham, 465-476, doi: 10.1007/978-3-319-62042-8_42

[27] Zimroz, R.; Hardygora, M.; Blazej, R. (2015). Maintenance of belt conveyor systems in Poland An overview, Niemann-Delius, C. (Ed.), Proceedings of the $12^{\text {th }}$ International Symposium Continuous Surface Mining - Aachen 2014, Lecture Notes in Production Engineering, Springer, Cham, 21-30, doi:10.1007/978-3-319-12301-1_3

[28] Straka, M.; Rosová, A.; Lenort, R.; Besta, P.; Šaderová, J. (2018). Principles of computer simulation design for the needs of improvement of the raw materials combined transport system, Acta Montanistica Slovaca, Vol. 23, No. 2, 163-174 